\title{
Effects of small-scale isolation and predation on fish diversity on experimental reefs
}

\author{
Jonathan Belmaker ${ }^{1,2, *}$, Nadav Shashar ${ }^{2,3}$, Yaron Ziv ${ }^{1}$ \\ ${ }^{1}$ The Departments of Life-Sciences, Ben-Gurion University of the Negev, PO Box 653, Beer-Sheva 84105, Israel \\ ${ }^{2}$ The H. Steinitz Marine Biology Laboratory, The Interuniversity Institute for Marine Sciences, PO Box 469, Eilat 88103, Israel \\ ${ }^{3}$ The Department of Evolution Systematics and Ecology, The Hebrew University of Jerusalem, Givat Ram, \\ Jerusalem 91904, Israel
}

\begin{abstract}
A positive correlation is often found between fish species diversity on coral reefs and their degree of isolation. We examined whether isolation creates differences in fish assemblages among reefs through changes in predation pressure. First, small artificial reefs were placed at increasing distances from a naturally continuous reef, over a sloping bottom. Species richness and density of each species increased with isolation. Next, artificial reefs were relocated, together with all their fish inhabitants, closer to the natural reef. Following relocation, resident fishes of the artificial reefs exhibited a sharp decline in numbers, while predatory fish density increased. Both video observations of the relocated artificial reefs and the correlation between piscivore aggregation and decline of the resident fishes revealed that the cause of decline was the strong predation around the artificial reefs. The decline was density-dependent, such that the per-capita rate of decline was higher on artificial reefs with higher fish density. This study shows that the impact of piscivores on resident fish is modified by small-scale isolation. The results suggest that the high density of fish on small, isolated reefs is enabled by low predation.
\end{abstract}

KEY WORDS: Reef fish $\cdot$ Artificial reef $\cdot$ Piscivores $\cdot$ Red Sea

\section{INTRODUCTION}

Patterns of species diversity in time and space are of great interest in community ecology (Rosenzweig 1995). A major theoretical development aimed to explain such patterns on isolated areas is the theory of island biogeography (MacArthur \& Wilson 1967). This theory postulates that species diversity on islands is determined through the balance between immigration and extinction rates. Accordingly, this diversity is expected to decrease with increased isolation due to reduced immigration from the species pool on the mainland. Indeed, since the theory of island biogeography has been published, many studies substantiated its predictions regarding the effect of increased isolation on lowering species diversity (e.g. Simberloff \& Wilson 1969, Williamson 1981, Rosenzweig 1995).

In coral reef systems, different levels of isolation can be found among reef patches ('islands') located at dif- ferent distances from continuous structures. Coral-reef patches support a diverse and abundant fish community (Sale et al. 1994). However, in contrast to the prediction of the island-biogeography theory, it has been shown that fish diversity on reefs can increase with distance from a natural, contiguous reef (Shulman 1985, Walsh 1985, Friedlander and Parrish 1998, J. Belmaker et al. unpubl. data). Moreover, patch reefs were found to contain more species than equivalent portions of continuous reefs (Ault \& Johnson 1998a, Stewart \& Jones 2001, Chittaro 2002). These effects are likely to be scale-dependent, since large reef patches do not necessarily show similar patterns (McClanahan \& Arthur 2001, Acosta \& Robertson 2002). Theoretical explanations for increased species richness in isolated reefs include reduced predation, reduced competition or less nest disturbance (Walsh 1985), additional food resources in the area surrounding the patch reef (Randall 1963 in Walsh 1985), and a longer edge relative to 
reef area associated with patch reefs than in continuous reefs, which offers an attractive habitat for species that use the sandy substrata for food and the nearby reef for shelter (Ault \& Johnson 1998a). However, in general, the apparent contradiction with the islandbiogeography theory has received relatively little attention in the literature and little experimentation has been done to test the above hypotheses.

Almost every fish on the coral reef starts as a pelagic larva (Leis 1991). The observed community structure of fish on a coral reef is therefore a product of an 'input' - typically through settlement of larvae onto the reef habitat, and an 'output' — through post-settlement processes such as mortality and emigration. There has been a considerable debate as to whether settlement patterns are sufficient to explain the subsequent population sizes (i.e. recruitment limitation; Doherty \& Williams 1988), or whether post-settlement processes act to modify settlement patterns. The latter can occur through different processes such as competition (Robertson 1996, Bay et al. 2001, Munday et al. 2001), predation (Hixon \& Beets 1993, Carr \& Hixon 1995, Beets 1997, Beukers \& Jones 1998, Connell 1998), and postsettlement relocation (Robertson 1988, Lewis 1997).

Accumulated evidence suggests that predation by piscivorous fish can have a significant effect on the abundance and diversity of coral reef fishes (Hixon \& Beets 1993, Carr \& Hixon 1995, Beets 1997, Holbrook \& Schmitt 2002, Webster 2003, Almany 2004). Piscivore abundance is not uniform, but patchy at several spatial scales (Caley 1995, Connell \& Kingsford 1998, Holbrook \& Schmitt 2003). These patterns of piscivore abundance may be important in determining the patterns of their prey species' abundance. The interaction between the long-term patterns of predator abundance and the short-term behavioral response of predators to prey should shape the nature of the impact piscivores have on fish distribution. Both the predators functional response (Holling 1959) and their aggregative response (Hassell 1966) are important in determining the strength of predation, and, ultimately, may resolve whether predation is strong enough to mask patterns of settlement. Recent evidence suggests that aggregation of piscivores around prey concentrations may be important for producing strong and density-dependent mortality of the prey (Anderson 2001, Webster 2003).

Predator-prey interactions may be contingent on the degree of isolation. Fish populations on isolated patch reefs - both piscivores and prey fishes - may assume a metapopulation with little post-settlement relocation (Ault \& Johnson 1998b), which could affect predatorprey interactions. It is well documented that predator density is lower on small isolated patches (e.g. Abensperg-Traun \& Smith 1999, Denys \& Tscharntke
2002, Michaux et al. 2002). Due to their small size, isolated reefs offer limited food supply and may not be able to support many local predators over time. In addition, the ability of predators to aggregate over prey may be reduced on isolated reefs since the risk of predation imposed on piscivores (by even larger predators) might preclude piscivores from moving freely among reefs. Indeed, Connell \& Kingsford (1998) and Connell (1998) found that predator abundance was higher on continuous reefs than on reef patches isolated within a lagoon.

Artificial reefs are increasingly being used to test ecological processes (e.g. Hixon \& Beets 1993, Caley \& St. John 1996, Beets 1997). It is possible to create artificial reefs identical in design, thereby controlling for variations that usually occur on natural reefs. In addition, artificial reefs are flexible in design and location, as well as easy to manipulate. The aim of this study was 2-fold: first, to confirm patterns observed in other studies regarding species diversity change with isolation (this was done by examining the diversity and composition of fish assemblages on experimental artificial reefs that differ in their degree of isolation) second, to test the hypothesis that predation pressure changes with isolation, such that more connected reefs experience higher predation pressure, potentially reducing species diversity (demonstrated by relocating artificial reefs to the vicinity of a continuous natural reef and monitoring fish abundance and predator aggregation on them).

\section{MATERIALS AND METHODS}

Study site and experimental design. We conducted this study at the Inter-University Institute for Marine Science (IUI) at the Israeli coast of the Gulf of Aqaba, Red Sea $\left(29^{\circ} 30^{\prime} \mathrm{N}, 34^{\circ} 56^{\prime} \mathrm{E}\right)$. We placed the artificialreef experimental setup at the location where the seafloor drops sharply from a depth of $12 \mathrm{~m}$ to a depth of $40 \mathrm{~m}$. Up to this drop, the bottom is covered by a continuous hard substrate with live coral cover. Further, beyond this sharp drop, few patchy and isolated corals are found on the sandy bottom. To examine the effect of isolation on fish community, we deployed 16 identical artificial-reef structures and monitored fish assemblages on them. We used small $\left(1 \mathrm{~m}^{3}\right)$ model units made of a metal frame on which a plastic mesh was added in a manner that increased the structural complexity, offering a variety of permanent and transient refuges, while still enabling visual census (Fig. 1).

The artificial reefs were submerged at a consistent depth of $10 \mathrm{~m}$ below the surface during September 2002, and placed in 4 distance groups according to their horizontal distance from the natural continuous reef $-0,12,25$ and $50 \mathrm{~m}$ away (Fig. 1). The artificial 


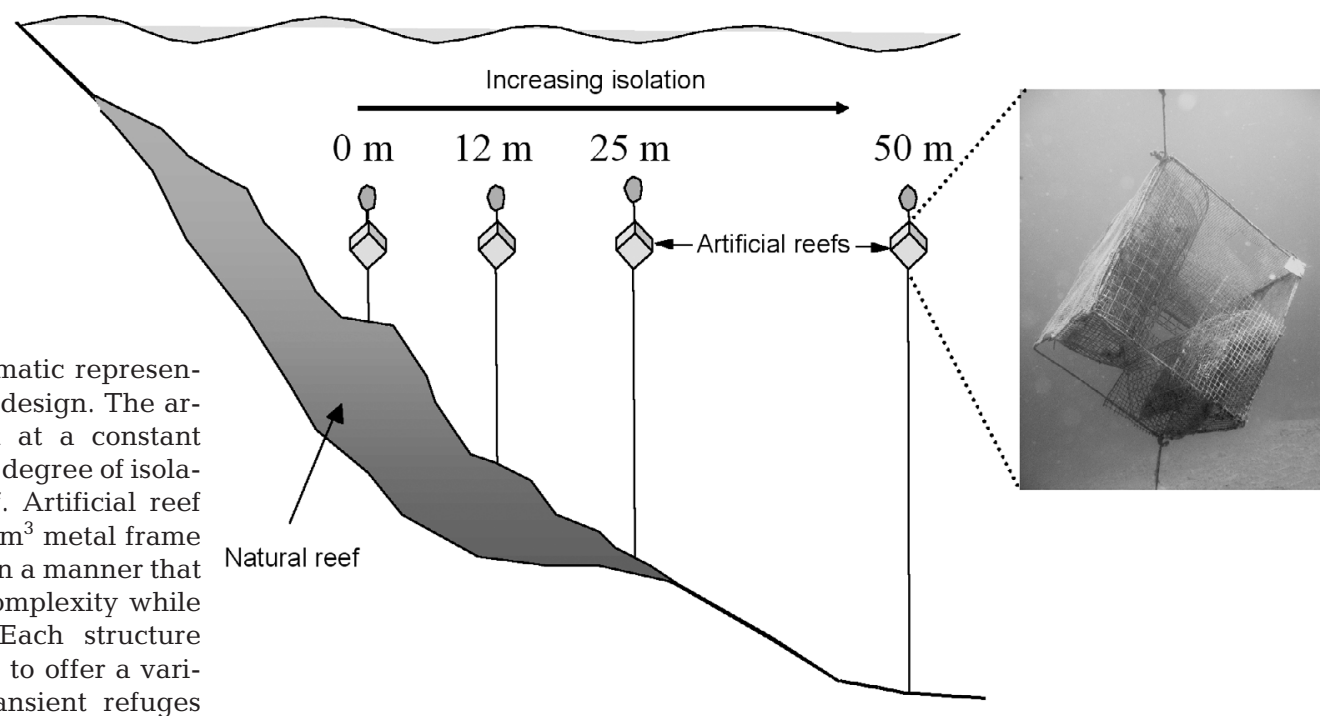

Fig. 1. A cross-shore schematic representation of the experimental design. The artificial reefs were floated at a constan depth, but at an increasing degree of isolation from the natural reef. Artificial ree units were made from a $1 \mathrm{~m}^{3}$ metal frame on which wire was added in a manner that increased the structural complexity while enabling visual census. Each structure contained 3 wire cylinders to offer a variety of permanent and transient refuges

reefs' averaged height above the bottom increased with isolation from 1.3 through $6.5,18.4$ and $33 \mathrm{~m}$, respectively. Subsequent reference to the artificial reefs will refer to their horizontal distance from the reef, although the vertical distance varies. For example, Distance 0 is directly above the natural reef although more than $1 \mathrm{~m}$ above the substrate. Each distance group had 4 replicas apart from the $50 \mathrm{~m}$ distance group of which only 2 replicas were intact at the end of the experiment. The distance between the replicates was at least $12 \mathrm{~m}$. Because the artificial reefs were suspended in mid-water, they were isolated from the natural reef both horizontally (i.e. distance from the natural reef) and vertically (i.e. distance above the ocean floor). This unique design allowed a conservative testing of isolation, since fish had to move in midwater to reach the reef. However, the design may have entailed other confounding effects involved with distance above the substrata and, consequently, we could not separate the effects of horizontal isolation and distance above the substratum. In the following sections we will use isolation to describe this combined effect of horizontal isolation and distance above the substratum.

To test our hypothesis that predation pressure changes with isolation, we relocated the artificial reefs after 12 mo of consistent isolation. Artificial reefs from the original distances of 12,25 and $50 \mathrm{~m}$ from the natural reef were moved to new locations adjacent to the natural reef, i.e. Distance 0. Relocation was done by completely covering each artificial reef with fine netting, trapping all resident fish inside the artificial reef. After covering, the artificial reefs were hung from a surface buoy, detached from their location and moved underwater with all the fishes inside to their new location. Occasionally, when large schools of fish were present on the reef, a few fishes were able to escape prior to the final closing of the net and stayed outside the netting. However, these fish did not leave the vicinity of the reef and even followed us during the relocation, settling back on the artificial reef once the netting was removed. Each artificial reef was surveyed both prior to and $24 \mathrm{~h}$ after relocation, allowing us to estimate fish loss due to the relocation process itself. The 24 h-after-relocation survey was used as a baseline for fish density for all subsequent analysis. Further surveys were conducted after 4, 7 and $14 \mathrm{~d}$, and then sporadically for the following 2 mo. Four artificial reefs were not relocated toward the natural reefs but were instead used as a control for the effect of the relocation process itself on fish assemblages. These control reefs were either relocated to a location at the same degree of isolation ( 2 reefs; 1 at $0 \mathrm{~m}$, and 1 at $12 \mathrm{~m}$ from the natural reef) or covered with netting and shaken vigorously ( 2 reefs, at distances of 12 and $25 \mathrm{~m}$ from the naturally continuous reef). These 2 groups were combined for data analysis.

Visual surveys. Fish populations on the artificial reefs were visually surveyed while SCUBA diving by a single surveyor (J.B.). The first 3 visual censuses were conducted at 3 mo intervals, starting in September 2002, after which 3 visual censuses were conducted at a 1 mo interval. Weekly surveys conducted during July and August 2003 improved the estimation of the transient fish population. The last survey took place during September 2003, making the total duration of the experiment approximately $1 \mathrm{yr}$.

All fishes, whether predatory, resident or pelagic, that swam within a distance of $0.5 \mathrm{~m}$ from the artificial reefs were recorded and sorted by species and size (by comparison with a ruler underwater). The number of 
schooling or shoaling species was estimated since it was impossible to conduct exact counts. The percent difference between consecutive estimates was not biased, i.e. did not differ from zero (mean $=-4 \%$, $95 \% \mathrm{CI}=12.9 \%$ ) and was independent of sample size above a minimum of 10 individuals per sample (Pearson's $r=-0.19, \mathrm{p}>0.47$ ).

We considered all fishes to be resident on the reef unless they left the artificial reef or took shelter outside it when approached by a diver, in which case they were recorded as transients (Walsh 1985). Patterns of abundance of piscivores and fishes transient to the artificial reefs were obtained both from scheduled monthly censuses during the summer of 2003 as well as from weekly surveys over a 2 mo period. We averaged the abundance of transients over the whole period per reef.

We classified fishes from the families Serranidae, Scorpaenidae, Carangidae, Muraenidae, Antennariidae and Fistulariidae as piscivores, providing that their total length (TL) was greater than $150 \mathrm{~mm}$. This value is slightly smaller than the $>200 \mathrm{~mm}$ TL used in previous research to characterize large piscivores (Connell 1998, Connell \& Kingsford 1998). We did not see members of other piscivore families on the artificial reefs throughout the entire study period. In addition, because examinations of gut content showed that many reef fish were capable of predation even though their diet was principally composed of other elements (Hiatt \& Strasburg 1960), we classified several species that are not classical piscivores (i.e. Parupeneus cyclostomus and Lethrinus nebulosus) as piscivores after they were observed attacking other fish on the artificial reef. We considered fish as potential prey when their TL length was smaller than $80 \mathrm{~mm}$, since this was the maximal length of fishes that were observed to be preyed upon by piscivores during the experiment.

Video observations. To observe the fishes' response to the relocation, 3 of the artificial reefs were videorecorded using a Hitachi VKC77E video camera placed in an underwater housing and connected online to a viewing, recording and controlling station on the shore. The reefs were monitored for $2 \mathrm{wk}$ following relocation for 3 or $6 \mathrm{~h}$ a day on the same days as the visual surveys. To assess predator abundance, we counted the number of predatory fishes that were present within $0.5 \mathrm{~m}$ of the reef over a $1 \mathrm{~min}$ time frame every $15 \mathrm{~min}$ and then averaged them over the $3 \mathrm{~h}$ of the recordings. The first video-recorded artificial reef had been in place for $12 \mathrm{mo}$, and was not relocated, hence serving as a control. We then video-recorded (at the same location) an artificial reef relocated from an original distance of $25 \mathrm{~m}$ from the natural reef, followed by a third artificial reef $12 \mathrm{~m}$ away.
Statistics. Statistical procedures were preformed primarily using the JMP software (Sall 2000). Parametric statistics were preformed only when the data passed the homogeneity-of-variance tests (both O'Brien's test [Olejnik \& Algina 1987] and the Brown-Forsythe test [Brown \& Forsythe 1974]. Since the raw data failed these tests we Box-Cox-transformed (Sokal \& Rohlf 2000) the numbers of individuals on the artificial reefs and square-root-transformed the number of species, thus ensuring homogeneity of variance. An artificial reef at a distance of $50 \mathrm{~m}$ that sank and lost individual fish before it was re-floated was excluded from analyses that compared numbers of fish individuals. Consequently, only 3 distance groups were used: those 0,12 and $25 \mathrm{~m}$ from the natural reef.

We examined the differences among groups in experiments which involved repeated surveys through time using multivariate repeated-measures analysis (Von Ende 2001). To analyze trends in time within a single treatment, we hand-calculated the nonparametric Page test (Siegel \& Castellan 1988). Analysis involving counts of piscivores or transients on the artificial reefs were highly variable; therefore nonparametric statistical tests were used and the Spearman's rank correlation replaced linear regression. To correlate the number of piscivores and the number of potential prey we used Spearman's rank correlation on all data points, combining replicas in space (i.e. between reefs) and in time (i.e. between surveys).

For multivariate analysis of assemblage structure we used similarity matrixes that were calculated with the Bray-Curtis index (Krebs 1999) on 4th root-transformed data in order to reduce the contribution of the common species (Clarke \& Warwick 1994). Significance of differences between sites in multidimensional space were calculated using analysis of similarity, ANOSIM (Clarke \& Warwick 1994). To identify species characteristic of the observed sample patterns, i.e. species that can be used to distinguish between distance groups in an analytical manner, we conducted species contribution to similarity analysis (SIMPER) (Clarke \& Warwick 1994). All multivariate analysis of assemblage structures were conducted with PRIMER-E software (Clarke \& Gorley 2001).

\section{RESULTS}

\section{Temporal patterns of species abundance, diversity and dynamics}

Overall, we counted 12862 fish belonging to 63 different species on the artificial reefs during the experiment. Of these, 12503 individuals (97.2\%) belonging to 38 species were resident on the artificial reefs. 
Although many species were observed, most were relatively rare, and the 2 common species Pseudanthias squamipinnis and Neopomacentrus miryae constituted $92 \%$ of all fish individuals. Fishes colonizing the artificial reefs were mostly juveniles, suggesting that colonization occurred primarily through settlement of larvae, and less through post-settlement relocation (though we cannot exclude the possibility of early postrecruitment dispersal).

The number of individuals and species increased significantly with time on artificial reefs from Distance Groups 12 and 25 m (Fig. 2, Page test, p < 0.05), but not on artificial reefs adjacent to the natural reef at distance $0 \mathrm{~m}$ (Page test, $\mathrm{p}>0.05$ ). The number of individuals increased for the first 9 mo after deployment, after which it either did not change or decreased (Fig. 2A). The large increase in fish density after 9 mo may correspond to a peak in recruitment at spring and the beginning of summer (Cuschnir 1991), followed by a minimal addition or even decline in individuals during the remaining summer months. Following the sharp initial increase, the number of species on Distance Group $50 \mathrm{~m}$ did not further increase with time (Page test, $\mathrm{p}>0.05)$.

We used multivariate analysis to compare the changes in species composition between the different surveys. Non-metric multi-dimensional scaling (MDS; Clarke \& Warwick 1994) showed clear grouping of reefs within surveys (average stress $=0.09$ ). An ANOSIM significance test confirmed that species composition differed significantly between surveys (2-way, distance and survey, crossed ANOSIM of 4th-root-transformed, unstandardized data, $\mathrm{p}<0.001$ ). However, we did not detect further changes in species composition beyond 9 mo from deployment. Species that were typical for the first survey, such as the goby Pleurosicya micheli, were relatively rare on subsequent surveys (SIMPER analysis). Large numbers of newly recruited Pseudanthias squamipinnis characterized the second survey, and all subsequent surveys were characterized by large numbers of Neopomacentrus miryae and P. squamipinnis, and to a lesser extent Anthias taeniatus (SIMPER analysis).

\section{Effect of distance from the natural reef}

We used the results of the visuals surveys to compare fish assemblage structure on artificial reefs located at different distances from the natural reef. Artificial reefs located off the natural reefs had a significantly larger number of resident species and individuals (repeated measures MANOVA on square-roottransformed data for species, $F_{3,9}=12.26$, $\mathrm{p}<0.01$; Box-Cox-transformed data for individuals, $F_{2,8}=21.5$,

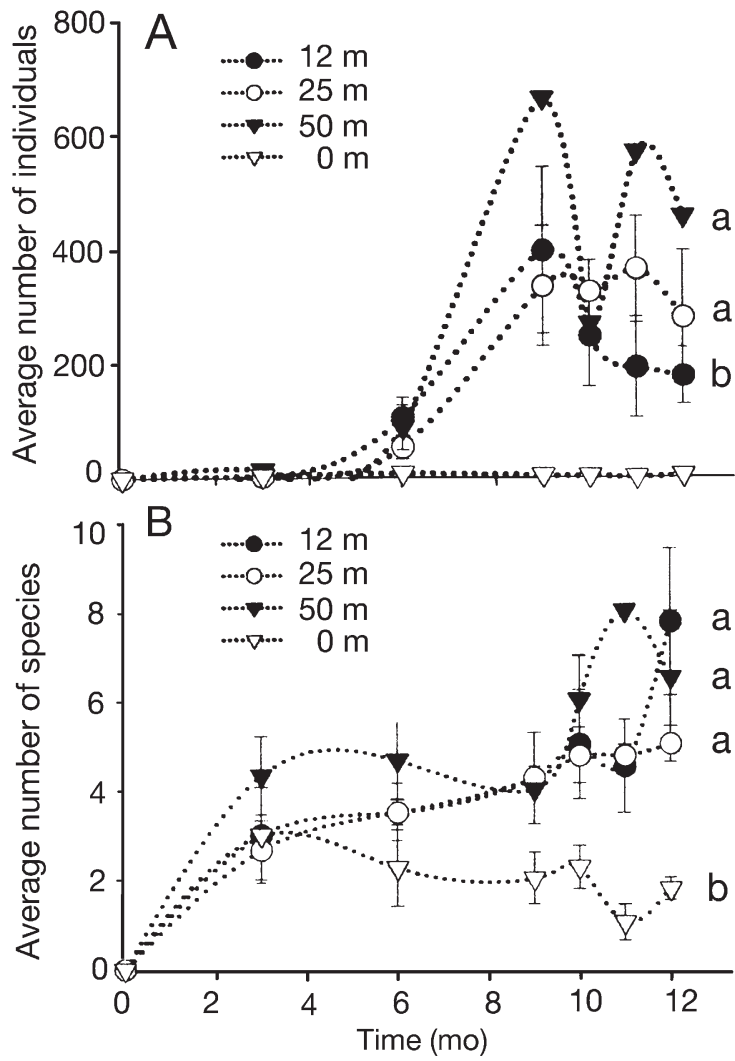

Fig. 2. Average ( $\pm 1 \mathrm{SE}$ ) number of resident (A) individuals and (B) species on an artificial reef vs time after deployment at different distances from the natural reef. Note that an artificial reef at Distance Group 50 that sank and lost individuals (but not species) before it was re-floated was excluded from panel A ( $(=1)$ but not from panel B $(n=2)$. Differences were analyzed using repeated-measures ANOVA on (A) Box-Coxtransformed data and (B) square-root-transformed data. Letters on the right join distances that are not significantly different (Contrast post hoc tests, $p>0.05$ ). Artificial reefs further from the natural reef (distances of 12, 25 and $50 \mathrm{~m}$ ) had more individuals and species than reefs adjacent to the natural reef

p < 0.001; Fig. 2). The increase was attributed to the difference between reefs adjacent to the natural reef (Distance 0), which remained depopulated throughout the study, to isolated artificial reefs at distances of 12 , 25 and $50 \mathrm{~m}$ from the natural reef (contrast post-hoc tests, $\mathrm{p}<0.05$ ). There was no significant difference in species or individuals among artificial reefs at distances of 12, 25 and $50 \mathrm{~m}$ (contrast post-hoc tests, p > 0.14). Importantly, the average number of transient fishes on the artificial reefs decreased significantly with distance from a natural reef (Spearman's rank correlation $\mathrm{r}=-0.66, \mathrm{p}<0.05)$.

Multivariate analysis was used to assess how location off the natural reefs affected resident fish assemblage structure. Cluster analysis as well as ANOSIM 
revealed that distance from the natural reef had a significant effect on fish assemblage structure (Fig. 3, ANOSIM on Bray-Curtis similarity index, on 4th-roottransformed, unstandardized data, $p<0.001$ ). Pairwise comparisons between distance groups showed that all distance groups that were located off the reef (at 12, 25 and $50 \mathrm{~m}$ ) were significantly different in assemblage structure from the reefs adjacent to the natural reef (Distance 0, p < 0.05). However, Distance Groups 12, 25 and $50 \mathrm{~m}$ did not differ significantly among themselves. These reefs were all characterized by many individuals of Neopomacentrus miryae, together with Pseudanthias squamipinnis and to a lesser extent Anthias taeniatus (SIMPER analysis). These species were almost completely absent from the artificial reefs that were close to the natural reef (i.e. distance 0), which were occupied mainly by the labrid Cheilinus mentalis (SIMPER analysis).

\section{Artificial reefs following relocation}

\section{Resident fish}

The number of fishes on the artificial reefs declined rapidly following their relocation to the continuous reef (Fig. 4). Repeated-measures MANOVA revealed that

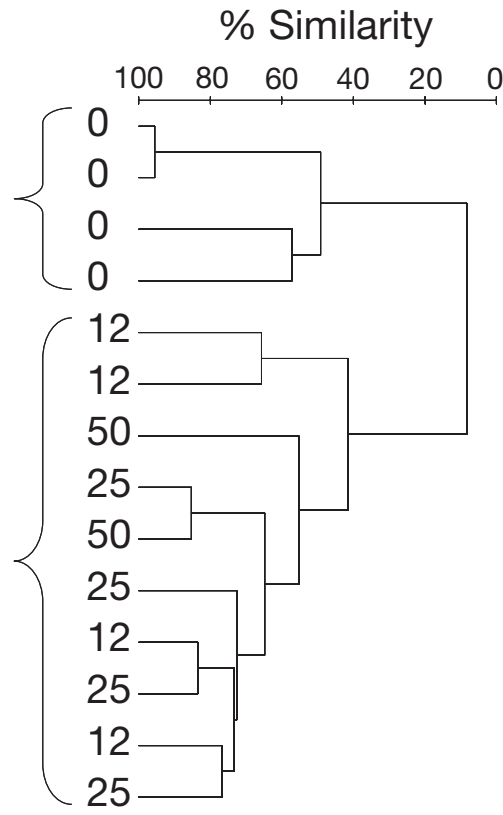

Fig. 3. Cluster analysis of similarity in fish assemblages on the artificial reefs of the last survey (September 2003). Similarity was calculated for resident fish using the BrayCurtis index on 4th-root-transformed, unstandardized data. Clustering was based on group averages. Low similarity in assemblage structure was found between the isolated reefs (Distances 12, 25 and $50 \mathrm{~m}$ ) and the reef adjacent to the natural reef (Distance 0 )

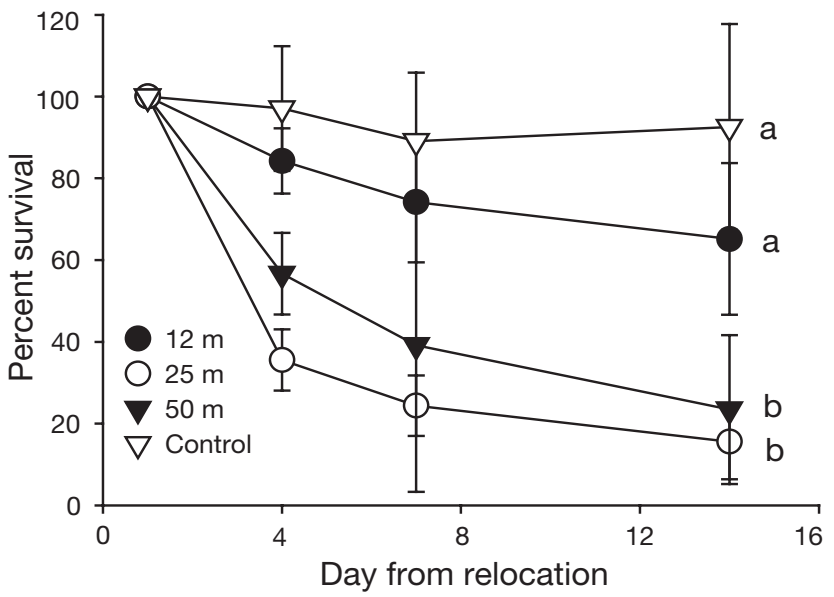

Fig. 4. Average ( $\pm 1 \mathrm{SE}$ ) percent survival of fish individuals (calculated relatively to Day 1) against day from relocation, for all resident fish on the artificial reefs. Letters join distances that are not significantly different (contrast post-hoc tests, following repeated-measures MANOVA, $p>0.05$ ). Artificial reef relocated from a distance of 25 and $50 \mathrm{~m}$ had lower survival than artificial reefs from $12 \mathrm{~m}$ or control reefs

the percent of individuals surviving was significantly different for artificial reefs that were relocated from different distances $\left(F_{3,10}=4.86, \mathrm{p}<0.05\right)$. Fish density on reefs that were brought from 25 and $50 \mathrm{~m}$ to a distance of $0 \mathrm{~m}$ declined faster than that of control reefs, i.e. reefs that did not change their degree of isolation (contrast post-hoc tests, $\mathrm{p}<0.05$ ). The number of fishes on reefs from $12 \mathrm{~m}$ declined slower than that of reefs brought from 25 and $50 \mathrm{~m}$ away $(\mathrm{p}<0.05)$, but did not differ from the control reefs $(p>0.3)$. To examine whether the rate of fish disappearance was related to the initial density, we plotted the per-capita disappearance rate (fish week $^{-1}$ initial density ${ }^{-1}$ ) against initial density (Fig. 5). A significant correlation (Spearman's rank correlation, $r=0.68, p<0.05$ ) between the percapita disappearance and the initial density support a density-dependent effect (this correlation remained valid even when we excluded an artificial reef that had extremely high initial densities of resident fish; Spearman's rank correlation, $r=0.68, p<0.05)$.

Although the artificial reefs as a whole showed a density-dependent decline in fish density, different species responded in different ways to the relocation. The most abundant species, Neopomacentrus miryae, declined very rapidly in number until only a few individuals remained on each reef $(3 \pm 6.4$ individuals after $2 \mathrm{wk}$, avg. $\pm \mathrm{SD})$. Hence, the number of $N$. miryae that disappeared within a week was strongly related to its initial density (Spearman's rank correlation, $r=0.96, \mathrm{p}<$ 0.001) while the per-capita decline was densityindependent (Spearman's rank correlation, $r=0.07$, $\mathrm{p}>0.85)$. The second-most abundant species, Pseudanthias squamipinnis, declined in number as well, 


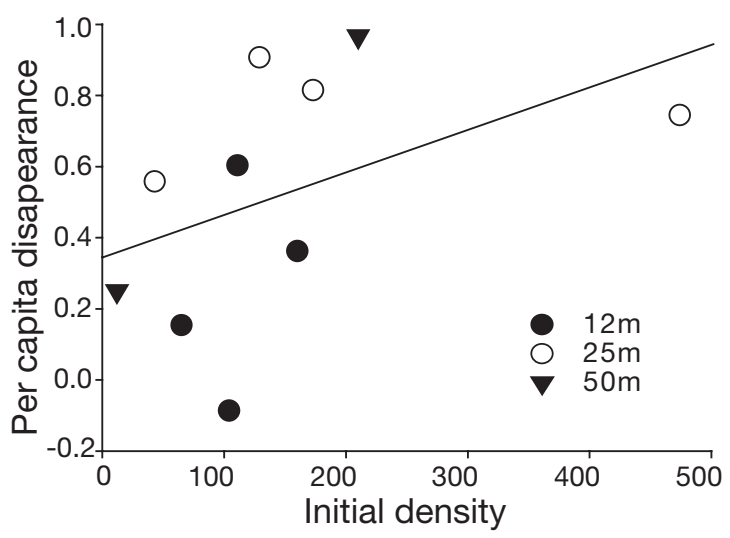

Fig. 5. Per-capita fish disappearance (i.e. change in the number of individuals after the first week following relocation divided by the fish density on the first day) vs initial fish density (number per artificial reef unit). The 2 variables are correlated (Spearman's rank correlation, $r=0.68 \mathrm{p}<0.05$ ), indicating a density-dependent effect

however the numbers of individuals that disappeared were relatively low and unrelated to the initial density (average decline of $18 \% \mathrm{wk}^{-1}$, Spearman's rank correlation, $\mathrm{r}=0.32, \mathrm{p}>0.36$ ). Other species occurred at low densities that did not allow analysis. Even though the number of fish on the artificial reefs declined rapidly in the first few days after relocation, subsequent changes were few, and fish numbers and assemblage composition did not change after the first few days.

\section{Piscivores}

Piscivores aggregated around relocated artificial reefs, and their numbers increased 50-fold following relocation, from $0.13 \pm 0.14$ (avg. $\pm \mathrm{SD}$ ) piscivores per survey to $6.75 \pm 6.24$. The number of piscivores on control reefs (artificial reefs located off the natural reef) decreased 6 -fold from $2.00 \pm 1.56$ piscivores per survey to $0.33 \pm 0.57$. Following an initial increase after relocation the number of piscivores on the artificial reefs declined significantly in Distance Group $25 \mathrm{~m}$ (Page test, $\mathrm{p}<0.05$ ), and declined, although only marginally significantly, in Distance Group $50 \mathrm{~m}$ (Page test, $L=55$, $\mathrm{n}=2, k=4, \mathrm{p}<0.06)$. However, the number of piscivores stayed consistently low and did not decline significantly on the control reefs (Page test, $\mathrm{p}>0.05$ ). The decline in the number of piscivores over time from relocation on the artificial reefs from distance group $12 \mathrm{~m}$ was not significant (Page test, $\mathrm{p}>0.05$ ). The number of piscivores was correlated to the density of potential prey on the experimental, relocated reefs (Spearman's rank correlation, $\mathrm{r}=0.64, \mathrm{p}<0.001$ ) but not on isolated control reefs (Spearman's rank correlation, $\mathrm{r}=$ $-0.062, \mathrm{p}>0.84)$. To calculate these correlations, we conducted several surveys of the same reef. However, since putative prey numbers declined substantially between surveys and since most piscivores were transients and showed high temporal variability, it is unlikely this biased the results.

To examine whether piscivores responded to the density of potential prey alone or to the relocation process itself, we tested whether the ratio between the number of predator individuals and prey individuals changed with time. We predicted that if predators responded to the relocation process itself the ratio between predator and prey will decrease with time from relocation. We conducted repeated-measures MANOVA on the piscivore-to-prey ratio (the ratio was taken between the square-root-transformed number of predators and log-transformed number of individuals, and was followed by angular transformation of the ratio; Sokal \& Rohlf 2000) with day from relocation as the repeated measure. The piscivore-to-prey ratio neither changed through time $\left(F_{3,5}=1.06, \mathrm{p}>0.44\right)$ nor with the distance from which the artificial reef was relocated $\left(F_{2,7}=2.42, \mathrm{p}>0.15\right)$. These results suggest that predators did not aggregate around the artificial reefs in response to the relocation process or the appearance of a new structure alone. However, baring in mind the low power of the analysis, we cannot exclude the effect of relocation entirely.

\section{Video analysis}

To reveal the cause of the decline in fish density in our relocated artificial reefs, we video-recorded 3 artificial reefs. The recordings showed an aggregative response of predators around relocated artificial reefs (Fig. 6). The number of aggregating predators seen by the camera was correlated to the density of resident fish (Pearson's $r=0.82, p<0.05)$. Furthermore, the recordings uncovered many direct attacks on the resident fish by predators. Nevertheless, exact quantification of these attacks was impossible due to their swiftness and the complexity of the artificial reefs. Indirect evidence provided further support to the hypothesis that the decline was caused mainly by predation: First, no new schools of either Neopomacentrus miryae or Pseudanthias squamipinnis were seen on the natural reef. Second, most of the examined reef fish belonged to species that are relatively sedentary and exhibit site fidelity. Third, in neither direct observations nor video monitoring was fish emigration out of the artificial reefs noted. Hence, though we cannot rule out this option, massive fish disappearance due to emigration was unlikely (e.g. Hixon \& Carr 1997, Forrester \& Steele 2000, Holbrook \& Schmitt 2002). Furthermore, limited emigration due to increased predation pressure does not significantly 


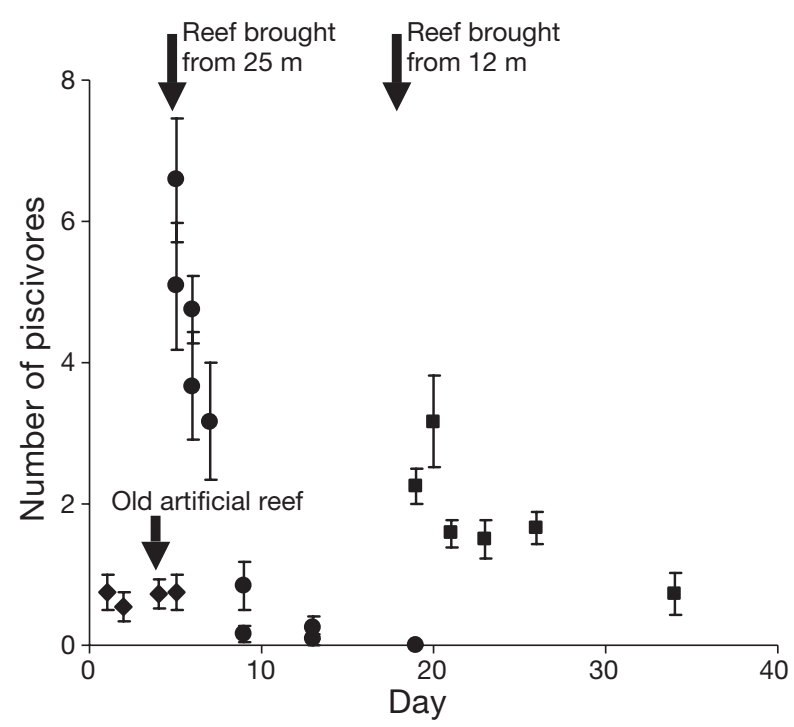

Fig. 6. Number of piscivores $( \pm \mathrm{SE})$ on an artificial reef at Distance 0 recorded during a $1 \mathrm{~min}$ time frame. All recordings were conducted at a single location. $\bullet$ = an old artificial reef (in location for $1 \mathrm{yr}$ ) with less than 10 resident fish, $\bullet=$ an artificial reef that was relocated from $25 \mathrm{~m}$ away and carried 173 individuals of resident fish $1 \mathrm{~d}$ after relocation, $\mathbf{\square}=$ an artificial reef that was relocated from $12 \mathrm{~m}$ away and carried 104 individuals of resident fish $1 \mathrm{~d}$ after relocation. Numbers of piscivores on artificial reefs initially increased after relocation, but eventually fell back to original numbers

alter our conclusions given that the ultimate outcome, reduced diversity on continuous reefs, is similar.

Piscivores aggregating around the reefs were taxonomically diverse and included relatively sedentary species such as the frogfish Antennarius commerson, as well as mobile species such as the jack Carangoides fulvoguttatus. Although jacks are mobile and were seen to swim into the ocean, they were not observed around control reefs but did, aggregate on reefs that were relocated toward the natural reef.

\section{DISCUSSION}

Artificial reefs that were placed away from the natural reef had more species and more individuals of fishes. Relocation of the artificial reefs near a natural continuous reef resulted in a rapid decline in fish density (decline of $53 \% \pm 35 \%$ in fish number over $1 \mathrm{wk}$, avg. \pm SD). This decline was associated with a 50-fold increase in piscivores density on the relocated reefs, while the control reefs exhibited a 6 -fold decline. This decrease on the control reefs might be attributed, though not verified, to movement of predators from these reefs toward the relocated reefs. These results suggest a causative relationship between piscivore aggregation and prey fish decline.
A unique aspect of our study, in contrast to the natural environment, is that isolation covaries with height above the substratum. Therefore, it is hard to distinguish the effects of isolation perse and confounded effects related to height above the substrate on fish assemblages (e.g. Rilov \& Benayahu 2002). For example, fish might be more reluctant to traverse open water than open sand. Although the artificial reefs do not necessarily mimic isolation on natural reefs, both show similar patterns of fish diversity. Similar to our study, patch reefs were found to support higher fish diversity than equally sized continuous reefs (Ault \& Johnson 1998a, Stewart \& Jones 2001, Chittaro 2002). In addition, small-scale isolation was shown to increase diversity of fish assemblages on small experimental reefs (Shulman 1985, Walsh 1985). The similarities suggest that insights from artificial reefs might prove useful in understanding natural ones. The limits of our experimental design do not rule out the significance of predation on continuous reefs as shown through reef relocation. The rapid decline of fish density on artificial reefs following relocation implies that short-term processes are at work, and therefore suggests that settlement patterns alone cannot suffice to explain the increase in fish diversity with isolation. Such rapidly acting agents may include emigration out of the artificial reefs or rapid mortality of the fish on the modular reef such as by means of predation.

The rate of decline in density was different for the 2 most common species. Neopomacentrus miryae declined rapidly, while the rate of decline was lower for Pseudanthias squamipinnis. Both species did not show density-dependent disappearance when analyzed separately. However, the total number of fish on an artificial reef did decline in a density-dependent manner. We believe that these results imply that piscivores aggregate around the artificial reefs in response to total fish density and not to the density of any particular species. Once predators reach the reef they do not consume prey according to their relative proportion but may have a preference toward a certain species. In our case, it seems that $N$. miryae is more susceptible to predation than P. squamipinnis. Behavioral observations show that while $P$. squamipinnis hid individually inside the reef when confronted with predators, $N$. miryae swam as a group around the reef in a frenzied manner. This behavior might be suitable when avoiding a solitaire predator, but inappropriate when faced with many predators together.

So why are small, isolated reefs diverse? Ault \& Johnson (1998a) proposed that the increase in fish diversity with isolation is caused by attraction of species from surrounding habitats and higher edge-to-area ratio associated with patch reefs as compared to continuous reefs. Our experimental design used identical reef-like 
structures that were suspended in mid-water, causing both horizontal and vertical isolation. Consequently, in this setting, the increase in fish density and richness with isolation was unlikely to be caused by accumulation of fishes from the surrounding habitat.

Predators aggregated over prey concentrations on artificial reefs following relocation, while isolated control reefs did not experience similar predator aggregation. This was true even when the degree of isolation was small and the isolated reef was clearly visible from the natural reef (only $12 \mathrm{~m}$ away, although over open water). The number of predators attracted to artificial reefs that were relocated towards a natural reef was correlated to the density of potential prey. Low densities due to high predation would imply that fish populations on continuous reefs may be below the carrying capacity of the habitat in terms of food supply, suggesting that predation is an important factor in reducing fish numbers and species diversity on continuous reefs. Predation pressure is likely to be higher on large or continuous reefs than on small patch reefs (Shulman 1985, Connell 1998, Connell \& Kingsford 1998, see also the recent work of Overholtzer-McLeod 2004). Put as a whole, isolated reefs have lower predation pressure and, hence, relatively higher species diversity compared to continuous reefs.

Reduced predation on small, isolated reefs can be attributed to the inability of predators to reach them, or to a lower ability of small reefs to support predators for long. However, reduced predation on isolated reefs can also arise by altering the behavioral response of predator to prey. Recent evidence suggests that predator aggregation can induce density-dependent mortality of prey (Anderson 2001, Webster 2003). Therefore, even if piscivores are able to reach an isolated reef individually, isolation might prevent aggregation, thereby reducing mortality.

In contrast to this experimental work, 2 studies found predator abundance (Stewart \& Jones 2001) and prey survival (Nanami \& Nishihira 2001) to be higher on patchy habitat than on continuous reefs. This is possibly caused by the scale dependence of the piscivores' response and distribution. Studies that found higher fishes diversity on isolated reefs were conducted on small, isolated reefs (Shulman 1985, Walsh 1985). However, Stewart \& Jones (2001) surveyed patch reefs that were much larger than the ones used in this study (mean of $115 \mathrm{~m}^{2}$ ), and were less isolated (10 m apart over sandy bottom). In the study of Nanami \& Nishihira (2001), the sandy habitat had a large proportion of hard cover $(25 \%)$. Therefore, isolation may only increase fish diversity of relatively small, isolated reefs (in the order of a few $\mathrm{m}^{2}$ ). The complex interaction between predators, prey and habitat heterogeneity is likely to be affected by the degree of isolation and patch size, as well as by other factors, including the fish's vagility, currents and water visibility.

Through reef relocation and differential isolation, our experimental study provides strong support for the hypothesis that, in coral-reef systems, high predation pressure on continuous reefs reduces species diversity. The finding regarding differences in predators abundance on mainland (e.g. continuous reef) vs islands (e.g. isolated reefs) is entirely in line with well-known island-biogeography studies in terrestrial systems, where islands show much lower diversity of predators (Rosenzweig 1995). However, contrary to terrestrial systems, isolated reefs support higher species diversity than continuous ones. So what makes coral-reef systems different? We believe that the islands' surrounding environment has a significant effect on determining species diversity. While in terrestrial systems the surrounding environment is hostile for all life stages of the organism, in coral-reef systems the open water provides the medium for larvae dispersal and serves as a source of recruitment. Nevertheless, it may still pose a barrier for adult stages distribution. Consequently, for reef fishes, small-scale isolation, such as examined in this study, does not represent a barrier for larvae dispersal. The combination of easy larvae dispersal with low post-settlement movement promotes a different outcome in coral- reef systems compared with terrestrial systems, namely a higher per-area species diversity on isolated reefs relative to a continuous one.

In a conservation context, artificial reefs are used to help in the rehabilitation of degraded habitats and in conserving biodiversity (Campos \& Gamboa 1989, Baine 2001), and may serve as recreational dive sites to lessen human pressure off adjacent natural reefs (Wilhelmsson et al. 1998). Maximizing fish diversity and abundance is important in all 3 cases. This study suggests that when constructing artificial reefs, small, isolated units will attain higher overall fish diversity than similar-sized connected reefs.

Acknowledgements. Special thanks to O. Ben Shafrut and G. Brachya for help with diving and to R. Motro, G. Pragai, U. Sogavker, Dr. E. Belmaker, and several anonymous reviewers for constructive comments. This research was conducted under permit no. 2002/13093 from the Israeli Nature Reserve Authority. This study was partly supported by the PADI foundation, the Lerner-Gray Memorial Fund of the American Museum of Natural History, the Italian Ministry of the Environment and grant no. 1206-2 from the Ministry of the Environment, Israel.

\section{LITERATURE CITED}

Abensperg-Traun M, Smith GT (1999) How small is too small for small animals? Four terrestrial arthropod species in different-sized remnant woodlands in agricultural Western Australia. Biodivers Conserv 8:709-726 
Acosta CA, Robertson DN (2002) Diversity in coral reef fish communities: the effects of habitat patchiness revisited. Mar Ecol Prog Ser 227:87-96

Almany GR (2004) Differential effects of habitat complexity, predators and competitors on abundance of juvenile and adult coral reef fishes. Oecologia 141:105-113

Anderson TW (2001) Predator responses, prey refuges, and density-dependent mortality of a marine fish. Ecology 82:245-257

Ault TR, Johnson CR (1998a) Spatial variation in fish species richness on coral reefs: habitat fragmentation and stochastic structuring processes. Oikos 82:354-364

Ault TR, Johnson CR (1998b) Spatially and temporally predictable fish communities on coral reefs. Ecol Monogr 68:25-50

Baine M (2001) Artificial reefs: a review of their design, application, management and performance. Ocean Coast Manage 44:241-259

Bay LK, Jones GP, McCormick MI (2001) Habitat selection and aggression as determinants of spatial segregation among damselfish on a coral reef. Coral Reefs 20:289-298

Beets J (1997) Effects of a predatory fish on the recruitment and abundance of Caribbean coral reef fishes. Mar Ecol Prog Ser 148:11-21

Beukers JS, Jones GP (1998) Habitat complexity modifies the impact of piscivores on a coral reef fish population. Oecologia 114:50-59

Brown MB, Forsythe AB (1974) Robust tests for equality of variances. J Am Stat Assoc 69:364-367

Caley MJ (1995) Reef-fish community structure and dynamics: an interaction between local and larger-scale processes? Mar Ecol Prog Ser 129:19-29

Caley MJ, St. John J (1996) Refuge availability structures assemblages of tropical reef fishes. J Anim Ecol 65:414-428

Campos JA, Gamboa C (1989) An artificial tire-reef in a tropical marine system: a management tool. Bull Mar Sci 44:757-766

Carr MH, Hixon MA (1995) Predation effects on early postsettlement survivorship of coral-reef fishes. Mar Ecol Prog Ser 124:31-42

Chittaro PM (2002) Species-area relationships for coral reef fish assemblages of St. Croix, US Virgin Islands. Mar Ecol Prog Ser 233:253-261

Clarke KR, Gorley RN (2001) PRIMER-E, Version 5. Plymouth Marine Laboratory, Plymouth

Clarke KR, Warwick RM (1994) Change in marine communities: an approach to statistical analysis and interpretation. Bourne Press, Bournemouth

Connell SD (1998) Effects of predators on growth, mortality and abundance of a juvenile reef-fish: evidence from manipulations of predator and prey abundance. Mar Ecol Prog Ser 169:251-261

Connell SD, Kingsford MJ (1998) Spatial, temporal and habitat related variation in the abundance of large predatory fish at One Tree Reef, Australia. Coral Reefs 17:49-57

Cuschnir A (1991) Taxonomic diversity, biological and ecological interspecific relationship, and annual cycle of distribution of ichthyoplankton in the northern end of the Gulf of Eilat (Red Sea). PhD thesis, Tel Aviv University, Tel-Aviv

Denys C, Tscharntke T (2002) Plant-insect communities and predator-prey ratios in field margin strips, adjacent crop fields, and fallows. Oecologia 130:315-324

Doherty PJ, Williams DM (1988) The replenishment of coralreef fish populations. Oceanogr Mar Biol 26:487-551

Forrester GE, Steele MA (2000) Variation in the presence and cause of density-dependent mortality in 3 species of reef fishes. Ecology 81:2416-2427
Friedlander AM, Parrish JD (1998) Habitat characteristics affecting fish assemblages on a Hawaiian coral reef. J Exp Mar Biol Ecol 224:1-30

Hassell MP (1966) Evaluation of parasite or predator responses. J Anim Ecol 35:65-75

Hiatt RW, Strasburg DW (1960) Ecological relationships of the fish fauna on coral reefs of the Marshall Islands. Ecol Monogr 30:65-127

Hixon MA, Beets JP (1993) Predation, prey refuges, and the structure of coral-reef fish assemblages. Ecol Monogr 63:77-101

Hixon MA, Carr MH (1997) Synergistic predation, density dependence, and population regulation in marine fish. Science 277:946-949

Holbrook SJ, Schmitt RJ (2002) Competition for shelter space causes density-dependent predation mortality in damselfishes. Ecology 83:2855-2868

Holbrook SJ, Schmitt RJ (2003) Spatial and temporal variation in mortality of newly settled damselfish: patterns, causes and co-variation with settlement. Oecologia 135:532-541

Holling CS (1959) The components of predation as revealed by a study of small-mammal predation of the European pine sawfly. Can Entomol 91:293-320

Krebs CF (1999) Ecological methodology, 2nd edn. AddisonWesley Educational Publishers, Menlo Park, CA

Leis JM (1991) The pelagic stage of reef fishes: the larval biology of coral reef fishes. In: Sale PF (ed) The ecology of fishes on coral reefs. Academic Press, San Diego, CA, p $183-230$

Lewis AR (1997) Recruitment and post-recruit immigration affect the local population size of coral reef fishes. Coral Reefs 16:139-149

MacArthur RH, Wilson EO (1967) The theory of island biogeography. Princeton University Press, Princeton, NJ

McClanahan TR, Arthur R (2001) The effect of marine reserves and habitat on populations of East African coral reef fishes. Ecol Appl 11:559-569

Michaux JR, De Bellocq JG, Sara M, Morand S (2002) Body size increase in insular rodent populations: a role for predators? Global Ecol Biogeogr 11:427-436

Munday PL, Jones GP, Caley MJ (2001) Interspecific competition and coexistence in a guild of coral-dwelling fishes. Ecology 82:2177-2189

Nanami A, Nishihira A (2001) Survival rates of juvenile coral reef fishes differ between patchy and continuous habitats. Bull Mar Sci 69:1209-1221

Olejnik SF, Algina J (1987) An analysis of statistical power for parametric Ancova and rank transform Ancova. Commun Stat Theory 16:1923-1949

Overholtzer-McLeod KL (2004) Variance in reef spatial structure masks density dependence in coral-reef fish populations on natural versus artificial reefs. Mar Ecol Prog Ser 276:269-280

Rilov G, Benayahu Y (2002) Rehabilitation of coral reef-fish communities: the importance of artificial-reef relief to recruitment rates. Bull Mar Sci 70:185-197

Robertson DR (1988) Abundance of surgeonfish on patchreefs in Caribbean Panama: due to settlement, or postsettlement events? Mar Biol 97:495-501

Robertson DR (1996) Interspecific competition controls abundance and habitat use of territorial Caribbean damselfishes. Ecology 77:885-899

Rosenzweig ML (1995) Species diversity in space and time. Cambridge University Press, Cambridge

Sale PF, Guy JA, Steel WJ (1994) Ecological structure of assemblages of coral-reef fishes on isolated patch reefs. Oecologia 98:83-99 
Sall J (2000) JMP, Version 4. SAS institute, Cary, NC

Shulman MJ (1985) Recruitment of coral reef fishes: effects of distribution of predators and shelter. Ecology 66: 1056-1066

Siegel S, Castellan NJ Jr (1988) Nonparametric statistics, 2nd edn. McGraw-Hill Book, New York

Simberloff DS, Wilson EO (1969) Experimental zoogeography of islands: the colonization of empty islands. Ecology 50:278-296

Sokal RR, Rohlf FJ (2000) Biometry, 3rd edn. WH Freeman, New York

Stewart BD, Jones GP (2001) Associations between the abundance of piscivorous fishes and their prey on coral reefs: implications for prey-fish mortality. Mar Biol 138:383-397

Editorial responsibility: Otto Kinne (Editor-in-Chief),

Oldendorf/Luhe, Germany
Von Ende CN (2001) Repeated measures analysis - growth and other time dependent measures. In: Schneider SM, Gurevitch J (eds) Design and analysis of ecological experiments, 2nd edn. Oxford University Press, New York

Walsh WJ (1985) Reef fish community dynamics on small artificial reefs: the influence of isolation, habitat structure and biogeography. Bull Mar Sci 36:357-376

Webster MS (2003) Temporal density dependence and population regulation in a marine fish. Ecology 84:623-628

Wilhelmsson D, Ohman MC, Stahl H, Shlesinger Y (1998) Artificial reefs and dive tourism in Eilat, Israel. Ambio $27: 764-766$

Williamson MH (1981) Island populations. Oxford University Press, Oxford

Submitted: April 14, 2004; Accepted: November 4, 2004

Proofs received from author(s): March 7, 2005 